\title{
EXPOSICCÃO À RADIAÇÃO IONIZANTE NATURAL EM TRABALHOS DE MAPEAMENTO GEOLÓGICO DE ÁREAS COM ELEVADO POTENCIAL RADIOATIVO.
}

\author{
Miquéas Barroso da Silva ${ }^{1}$; Luiz Cláudio Rocha ${ }^{3}$; Ulisses Antonio Costa ${ }^{1}$; Antonio Charles da Silva Oliveira ${ }^{1}$, Marcely \\ Pereira Neves', Marcelo Esteves Almeida ${ }^{1}$, Lucy Takehara ${ }^{2}$ e Diogo Alves de Sordi ${ }^{2}$ \\ 1 - SBG/CPRM - Manaus; 2 - SBG/CPRM - Brasília; 3 - Escola Superior de Tecnologia da UEA
}

\begin{abstract}
Copyright 2011, SBGf - Sociedade Brasileira de Geofísica
This paper was prepared for presentation during the $12^{\text {th }}$ International Congress of the Brazilian Geophysical Society held in Rio de Janeiro, Brazil, August 15-18, 2011.

Contents of this paper were reviewed by the Technical Committee of the $12^{\text {th }}$ International Congress of the Brazilian Geophysical Society and do not necessarily represent any position of the SBGf, its officers or members. Electronic reproduction or storage of any part of this paper for commercial purposes without the written consent of the Brazilian Geophysical Society is prohibited.
\end{abstract}

\begin{abstract}
$\mathrm{T}$ This paper deals with the characterization of researcher's exposure to natural ionizing radiation, during gamaspectrometry survey on ground geophysics, as a complementary tool for geological mapping of REE (Rare Earth Elements) with high radioactive potential. The legislation related to this issue is mainly directed to the productive chain comprising the extraction, transport and environmental disasters, but never mentioning the previous activities, as is the discovery of the ore that originates this chain. Researcher's exposure, even in small doses, must be taken into account, since it's not possible to measure long term damage on exposed individuals. For working benefits, the statement is that it's only necessary to configure the existence of ionizing radiation, not depending on magnitude and period of exposure of radioactive agente.
\end{abstract}

\section{Introdução}

De forma geral, os trabalhos de pesquisa mineral não tem a preocupação com os riscos ambientais, no que diz respeito a segurança e saúde ocupacional, que os pesquisadores estão submetidos no desempenho de suas atividades. Nossos bens minerais são na maioria das vezes, condições anômalas de concentração de determinados elementos químicos, que dependendo do bem mineral, essas concentrações podem ser economicamente vantajosas, mas extremamente prejudicial a saúde das pessoas que estão envolvidas desde a sua descoberta (pesquisa) até seu destino final de descarte, se não houver preocupação com as condições nocivas que esses elementos oferecem a saúde humana. Bons exemplos de elementos nocivos a saúde humana, quando mau trabalhados, são os utilizados como fontes de energia radioativa, tais como os ETRs (Elementos Terras Raras), que também são freqüentemente empregados em produtos com tecnologia de ponta, tais como "iPhones, iPads, computadores, televisores, materiais de alta resistência usados em motores de aviões e cápsulas de foguetões. Os ETR's, atualmente tem sido citados com certa freqüência em manchetes apontando estes como: tão ou mais importantes que o ouro ou o petróleo, cujo o detentor de mais de $97 \%$ da produção mundial é a China, alvo de inúmeras polêmicas e discussões sobre as restrições impostas a sua exportação. As radiações ionizantes é um perigo silencioso que pode causar danos devastadores a saúde humana compreendendo o individuo diretamente submetido a radiação podendo estender-se até os seus descendentes.

Este trabalho compreendeu uma monografia apresentada ao programa de Pós-graduação em Engenharia de Segurança do Trabalho da Universidade Estadual do Amazonas, que qualificou o primeiro autor, para obtenção do título de Engenheiro de Segurança do Trabalho. No seu contexto geral procura mostrar a exposição de trabalhadores à radiações ionizantes naturais, na execução de trabalhos de pesquisa para mapeamento geológico, e enquadrar na legislação existente que trata principalmente de processos, transportes e contaminações, mas não é clara no que diz respeito, sobre as ocorrências naturais (rochas e solos) de radioatividade como fator determinante de exposição a estas irradiação.

\section{Contexto Geológico Regional}

Resumidamente o contexto geológico da área de estudo compreende o domínio Cinturão Guiana Central, o qual é composto por um embasamento paleoproterozóico formado pelas unidades: (1) Suíte Metamórfica Rio Urubu, que é constituída por ortognaisses e metagranitoides (Fraga \& Araújo 2000 a); (2) Suíte Intrusiva Serra da Prata, constituída por corpos charnoquitoides (Fraga 2002). Este embasamento apresenta-se intrudido pelas unidades mesoproterozóicas: (3) Anotosito Repartimento (c.a 1.527 $\mathrm{Ma}$ ), representado por corpos intrusivos de composição Anortosítica; (4) Gabro Caracaraí (c.a $1.646 \quad \mathrm{Ma}$ ) representado por corpos intrusivos de composição gabroíca e a (5) Suíte Intrusiva Mucajaí (c.a 1.544 Ma), que é constituída por granitos rapakivi. No fanerozóico instalou-se o rift Tacutu, seguido das intrusões de corpos alcalinos mesozóicos da (6) Suíte Alcalina Apiaú. Por fim, no Cenozóico estas rochas sofreram alteração supergênica, desenvolvendo um manto de intemperismo frequentemente observado na região, com crostas lateríticas. Figura 1.

\section{Metodologia de trabalho}

O Levantamento gamaespectrométrico utilizado como suporte para o trabalho de mapeamento geológico compreendeu medidas de radiotividade ao longo de picadas abertas sobre dois alvos definidos para pesquisa de ETR (Elementos Terras Raras) este levantamento orientou-se segundo duas malhas. 


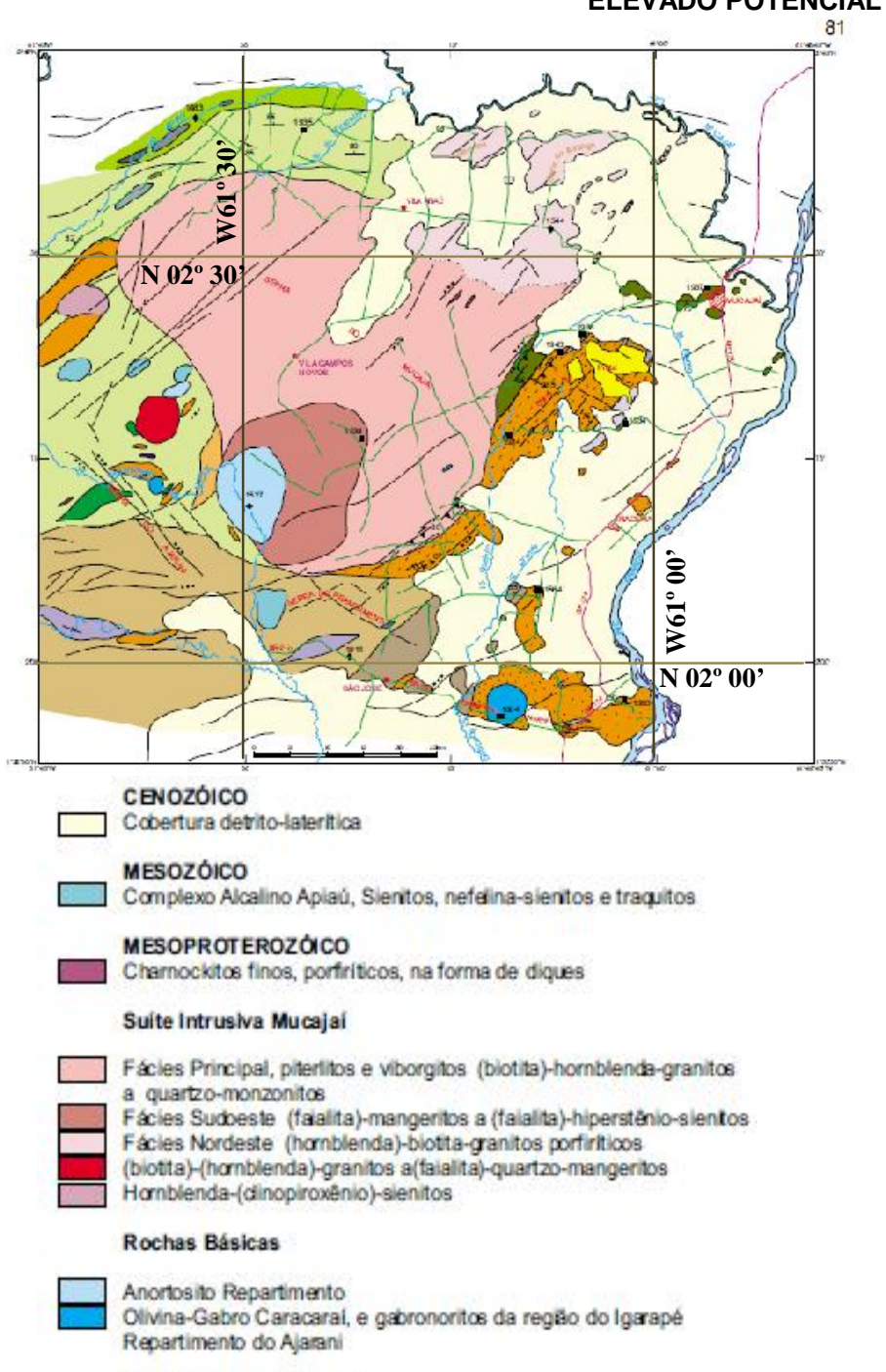

PALEOPROTEROZÓICO

Suite Intrusiva Serra da Prata

Charnockitos com subordinados hiperstęnio-quartzo-slentos; quartzo-mangentos: quartzojotunitos.

7 Corpo do lgarape Grande $\square$ corpo da Serra da Prata

(Cinopiroxénio)-(hornblenda) biot tha-granitos do corpo do igarapé Roxinho

Ortognaisses e Granitóides Foliados

Gnaisse Igarape Branco - biotta-homblenda-gnaisses a allanita Gnalsse Igarape Mracelha - hornblenda-biotta-gnais ses a titanita , grossos, ocelares ( $)$ ) e finos a médos ( 0 ) Slenogranitos foliados

Hornblenda-biotita-gnaisses tonaliticos

(Homblenda)-biotta-gnaisses

Gnalsses sienograniticos

Biotita-(hornblenda)-gnaisses finos a titanita

Rochas Máficas

Hornblenda-noritos e Hornblenda-gabronoritos

(Biot ita)-gabros e (biotta)-gabronorito

Dioritos

Lineamertos estruturais (taihas, fraturas ou zonas de cisalhamento)

-.. Cataclasitos

T Zona de clsalhamento $D_{2}$ transpressiva, dextral

T. Follaçäo $\$$

Follaçato milonitica $S$, e lineaçă L,

Figura 2 - Mapa Geológico extraído da dissertação de doutorado de Fraga 2002.
A primeira contendo uma linha base com $4,8 \mathrm{~km}$ de extensão, seccionada por duas transversais de dimensões $4,7 \mathrm{~km}$ e $7,6 \mathrm{~km}$ respectivamente. A segunda, contendo uma linha base com 10,7 km de extensão, seccionada por duas transversais de $5,5 \mathrm{~km}$. As amostragens geológicas/geoquímica foram espaçadas a cada $50 \mathrm{~m}$ e as medidas de radiação destas amostras foram realizadas fazendo uso de um Gamaespectrometro modelo RS-230. As leituras foram realizadas na função "assay" por um período de cento e vinte segundos e simultaneamente, foram realizadas medidas na função "suvay" para gerar perfis contínuos ao longo das picadas que compreendem os alvos.

Estes dados foram interpolados pelo método de mínima curvatura fazendo uso de rotinas pré-estabelecidas pelo software Oasis Montaj V. 8.0 da Geosoft e apresentados em forma de grids com distribuição de cor contendo as cores mais quentes (tons de vermelho) as maiores dosagens e cores mais frias (tons de azuis) as menores dosagens da Radioatividade.

A caracterização da exposição dos trabalhadores à fonte radioativa ionizante natural durante a execução dos trabalhos procurou enquadrar na legislação para trabalhos realizados sob essas condições

\section{Resultados}

Os dados radiométricos obtidos inicialmente para fins de mapeamento geológico foram adquiridos na unidade $\mu R / h$ (micro roentgem por hora). Para este estudo, que tem o propósito de mostrar a exposição dos pesquisadores/trabalhadores à irradiação ionizante natural, como fator de possível dano a saúde ao longo de determinado tempo (efeito estocástico). E pelo motivo de corriqueiramente ser observado na literatura a utilização das unidades Gray (Gy) e Silvert (Sv) como base para avaliação de exposição à estas radiações, optou-se pela conversão dos dados obtidos durante os trabalhos de campo, fazendo uso da relação:

$$
1 \text { Gray }(\text { Gy) }=1 \text { Silvert }(S v)=100 R \text { (Roentgem) }
$$

Ao longo do trabalho desenvolvido sobre o Alvo 1, foram obtidos valores de dosagem variando no intervalo entre 32,3 a 3626,37 nSv/h (nano silvert por hora) Figura 2. A maior exposição a radiação compreende a linha transversal 1 e uma boa parte da Linha Base, entretanto todo alvo compreende uma exposição média da doses de $325,85 \mathrm{nSv} / \mathrm{h}$, conforme análise estatística apresentada no histograma obtido automaticamente pelo software. O ponto máximo de Dose observado neste alvo compreende o valor de $3626,37 \mathrm{nSv} / \mathrm{h}$ possivelmente de uma rocha sienitica alterada por lateritização.

No Alvo 2, foram obtidos valores de dosagem no intervalo entre 29,5 a 5374,4 nSv/h (nano silvert por hora), Figura 3. A maior exposição a radiação compreende a intersecção entre a linha transversal 1 e a linha base e também a região intermediaria da transversal 2 próximo a intersecção com a linha base. De forma geral a exposição média da dose neste alvo é 208,26 nSv/h, e o ponto máximo da Dose observado neste alvo compreende o valor de 5374,4 nSv/h, resultante de um solo inconsolidado de coloração marrom. 

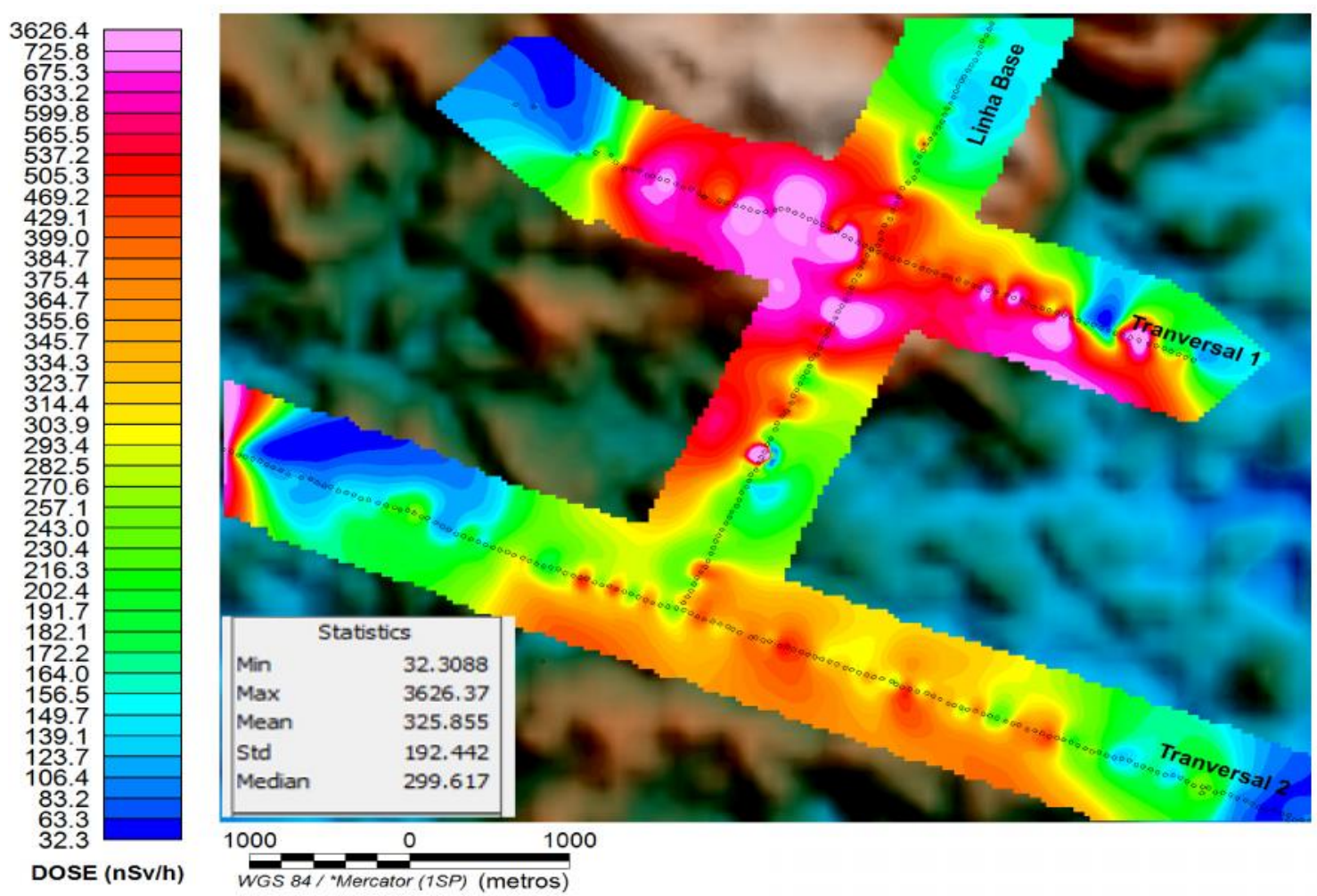

Figura 2- Imagem do grid obtido pelo método de interpolação de mínima curvatura dos dados radiométricos da Dose em unidade de nano silvert por hora (nSv/h) do Alvo 1, disposta sobre o modelo digital do terreno e representação da estatística do dado.

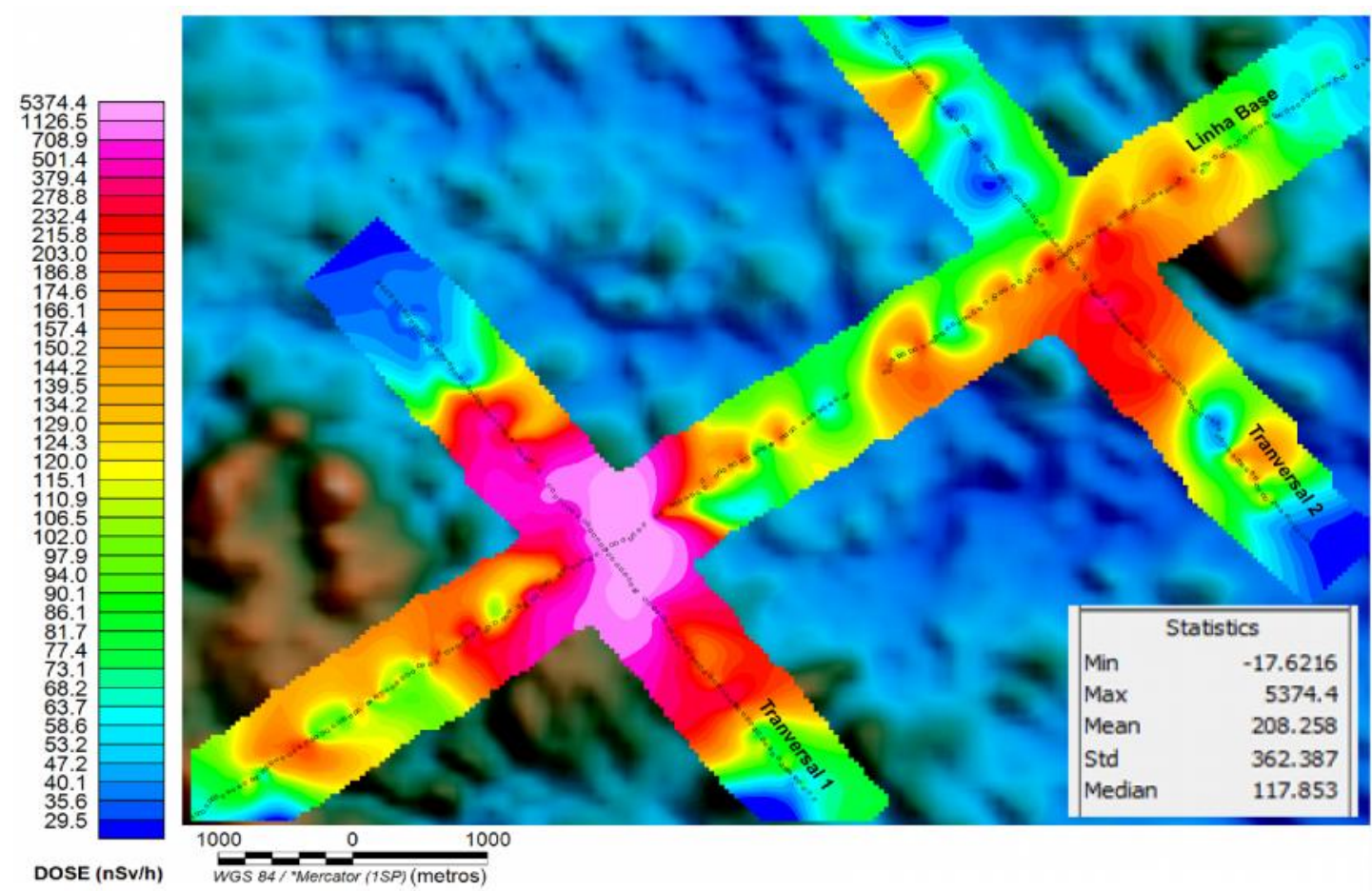

Figura 3- Imagem do grid obtido pelo método de interpolação de mínima curvatura dos dados radiométricos da Dose em unidade de nano silvert por hora (nSv/h) do Alvo 2, disposta sobre o modelo digital do terreno e representação da estatística do dado 


\section{Conclusões}

Considerando o tempo de dois minutos para cada estação geológica/geofísica e deslocamento entre as estações que distam cinquenta metros entre si, o tempo decorrido para aquisição do dado no intervalo de um quilometro foi de aproximadamente sessenta minutos. A produção diária para o trabalho de mapeamento geológico foi de aproximadamente dois quilômetros, levando em conta o tempo de retorno e parada para almoço realizado em campo, a permanência sobre os alvos totalizaram aproximadamente 4 horas. Tempo este considerado de grande relevância quando relacionado a exposição a radiação ionizante, uma vez que, a dimensão total dos dois alvos compreendem cerca de 39 $\mathrm{km}$, configurando um exposição incontínua de quase 20 horas.

A exposição a radiação no desenvolvimento deste trabalho parece não ser grande coisa levando em consideração a magnitude da dose abaixo de limiares estabelecidos na legislação (ASSEC/01/02/03 1993, CNEN 1988), mas a probabilidade de ocorrência de um câncer radioinduzido a longo prazo (podendo chegar a 40 anos apos a exposição) deve ser um efeito estocástico que não pode ser descartado. Por definição este efeito considera a probabilidade de ocorrência proporcional à dose de radiação recebida, sem a existência de limiar, ou seja, doses pequenas, abaixo dos limites estabelecidos por normas e recomendações de radioproteção, podem induzir a esses efeitos retardados. Um outro exemplo, que também não pode ser descartado, são os efeitos genéticos ou hereditários, que aparecem no descendente da pessoa irradiada em função do dano produzido em células dos órgãos reprodutores, que tem caráter cumulativo e independe da taxa de absorção da dose. (Gonzales \& Rigolon 1994)

As doses baixas, não produzirão efeitos imediatos, mas não pode ser negligenciada a possibilidade das lesões a longo prazo. Os efeitos retardados principalmente 0 câncer, complica bastante a implantação de critérios de segurança nos trabalhos com exposição a radiação. Hoje em dia ainda não é possível usar critérios clínicos, pois quando aparecem os sintomas o grau do dano já pode ser severo e letal além de ultrapassar o tempo de vida laboral do trabalhador. Infelizmente os critérios utilizados são baseados em hipóteses estabelecidas sobre critérios físicos, extrapolações matemáticas e comportamentos estatísticos.

A legislação existente insiste em estabelecer limites de tolerância, tempo de exposição e fracionamento de percentuais para a concessões de valores pecuniários mediante áreas divididas por intensidade de radiação que estão submetidos. Apesar de considerarmos as ações e omissões dos trabalhadores, essa prática induz os mesmos à permanecer em faixas com o percentual "mais favorável" ferindo em cheio as recomendações básicas estabelecidas no principio ALARA (independente do valor atribuído ao risco potencial, deve-se sempre buscar reduzir a exposição a valores tão baixos quanto exequíveis, observada a relação custo-benefício).
Dever-se-ia como regra, considerar a natureza bipolar de existência ou não de risco, pois não se pode inferir uma relação numérica por faixas/áreas que associem a dose potencial e o tempo de exposição na área de risco, e estabelecer um sistema de qualificação de áreas, livres e restritas. Onde a definição de área restrita, entende-se como todas as áreas de trabalho que possuam fontes de radiação ionizante, não importando sua magnitude.

Nesse caso a exposição as radiações ionizantes, mesmo que em pequenas ordem de grandeza, são passives de representar risco a saúde humana, pois é suficiente a sua presença, independente da sua magnitude ou tempo de exposição.

\section{Referências Bibliográficas}

ASSEC/ 03, de Dezembro de 1993, "Adicional de Irradiação Ionizante: Texto Complementar das Associações dos Servidores da CNEN", Rio de Janeiro.

ASSEC/01 e 02/, "Avaliação das Associações de Servidores da CNEN sobre Aplicação de Adicional de Irradiação Ionizante", Julho de 1993.

CNEN NE 3.01, "Diretrizes Básicas de Proteção Radiológica", Julho de 1988.

FRAGA, L.M.B.; ARAÚJO, R.V.; HADDAD, R.C. Suíte Metamórfica Rio Urubu. In: CPRM, Programa Levantamentos Geológicos Básicos - PLGB. Roraima Central, Folhas NA.20-X e NA.21-V, Estado de Roraima, escala 1:500.000. Brasília/ SUREG-MA, p. 38-48. 1CD-ROM. 2000a.

FRAGA, L.M. A Associação Anortosito - Mangerito - Granito Rapakive (AMG) e suas encaixantes paleoproterozóicas: evolução estrutural, geocronologia e petrologia. Tese de Doutorado. Centro de Geociências, Universidade Federal do Pará, Belém, 2002, 351 p.

Gonçalez, O.L. e Rigolon, L.S., "O Trabalho com Radiação Ionizante no RJU, Segundo a Lei 8.270 e Respectiva Regulamentação", III Congresso Geral de Energia Nuclear, Junho de 1994". 